\title{
Qualidade fisiológica de sementes de arroz submetidas à radiação gama
}

\author{
Physiological quality rice seed submitted to gamma radiation
}

\author{
Helen Lúcia da Cruz Miranda ${ }^{{ }^{*}}$ Vera Lucia Bobrowski ${ }^{I I}$ Maria Angela André Tillmann ${ }^{\mathrm{I}}$ \\ Luciana Bicca Dode ${ }^{\mathrm{III}}$ Geri Eduardo Meneghello
}

\section{RESUMO}

O objetivo deste trabalho foi avaliar os efeitos da radiação gama $\left(\mathrm{Co}^{60}\right)$ na qualidade fisiológica de sementes de arroz. O estudo foi realizado em três ensaios. No primeiro ensaio, sementes de arroz foram irradiadas com doses de $0 ; 1$; 2,5 e 5Gy e, para o segundo e o terceiro ensaio, as sementes foram submetidas a envelhecimento acelerado, antes da irradiação. No segundo ensaio, as sementes foram dividas em úmidas e secas após envelhecimento acelerado e, então, foram irradiadas nas doses $0 ; 1 ; 2,5$ e 5Gy. No terceiro ensaio, as sementes foram secas após o envelhecimento acelerado e irradiadas com doses de 0, 10, 25 e 50Gy. Para avaliação dos efeitos fisiológicos da radiação gama, foram realizados teste de germinação - TG, índice de velocidade de germinação IVG e crescimento de plantas (comprimento de parte aérea e sistema radicular e massa seca total), em todos os ensaios. Foram determinadas as atividades enzimáticas da fosfatase ácida e alfa amilase nas sementes secas, no segundo ensaio. Os resultados obtidos nos ensaios indicam que as doses de radiação gama estudadas não afetam a qualidade fisiológica das sementes de arroz.

Palavras-chave: Oryza sativa, irradiação, mutagênico.

\section{ABSTRACT}

The objective of this research was to evaluate the effects of the gamma radiation $\left(\mathrm{Co}^{60}\right)$ on the physiological quality of rice seeds. The research was carried out through three tests; in the first test rice seeds were irradiated at dosages of $0 ; 1 ; 2.5$ and 5Gy, while for the second and third tests the seeds were subjected to accelerated aging before being irradiated. For the second test the seeds were divided into wet and dry and both groups subjected to accelerated aging previous to irradiation at dosages of $0 ; 1 ; 2.5$ and 5Gy. For the third test the seeds were dried after being subjected to accelerated aging, and then irradiated at dosages of 0, 10, 25 and 50Gy. To assess the physiological effects of the gamma radiation, all seeds were tested for germination and their germination speed index recorded. Seedling growth was graded through the measurement of the lengths of the first leaf and seminal root system and total seedling dry weight, across all tests. The enzymatic activity of acid phosphatase and alpha-amylase was measured on dry seeds from the second test. The results from all tests indicate that the applied gamma radiation dosages did not cause any changes to the physiological quality of rice seeds.

Key words: Oryza sativa, irradiation, mutagens.

\section{INTRODUÇÃO}

A cultura de arroz possui uma estreita base genética e a busca por melhores cultivares é uma constante preocupação entre os melhoristas dessa espécie. A utilização de mutações como fonte de variabilidade constitui, desde a metade do século XX, ferramenta adicional na busca de novas variedades (GAUL, 1970). A radiação gama é considerada um dos principais indutores de mutação e de aberrações cromossômicas estruturais (PIMENTEL, 1990), sendo seus efeitos influenciados por diversos fatores. Dentre esses fatores, podem-se citar as condições de armazenamento após a irradiação (CONGER \&

IPrograma de Pós-graduação em Ciência e Tecnologia de Sementes, Universidade Federal de Pelotas (UFPel), CP 354, 96010-900, Pelotas, RS, Brasil. E-mail: helenllc@gmail.com.*Autor para correspondência.

IDepartamento de Genética (IB), UFPel, Pelotas, RS, Brasil.

IIUniversidade Católica de Pelotas (UCPel), Pelotas, RS, Brasil. 
CARABIA, 1972), o genótipo dos indivíduos (BAHL \& GUPTA, 1982), o modo de exposição do material (IQBAL \& ZAHUR, 1975), a presença de algumas substâncias químicas (KUMAR, 1991), a fase do ciclo celular (GUDKOV \& GRODZINSKY, 1982), a dosagem de radiação (SANTOS, 1993), o grau de ploidia dos cromossomos (BROCK, 1980), o conteúdo de DNA por genoma haplóide (PLEWA et al., 1993) e o nível de oxigênio (BUMP et al., 1982).

Por meio do uso de radiações ionizantes, foram obtidos mutantes com características de maior produtividade, precocidade, menor porte, maior resistência a doenças, pragas e acamamento, que foram utilizados na obtenção de novas variedades de diversas espécies de interesse agronômico (MIKAELSEN, 1971).

As respostas do material biológico a agentes mutagênicos é dependente de uma interação complexa entre o mutagênico e o material biológico ou entre este e as substâncias formadas pelo mutagênico no organismo vivo. Os efeitos causados por mutagênicos sobre organismos vivos têm sido estudados em termos do entendimento dos princípios físicos e/ou químicos que governam as reações dessas substâncias com os componentes celulares, analisando a integridade da membrana, os índices de divisão mitótica, o conteúdo de RNA, além dos efeitos fisiológicos sobre a germinação das sementes, o índice de velocidade de germinação e a sobrevivência (GAUL, 1970).

Pesquisas desenvolvidas em diversos países revelam que, por meio do emprego de radiações ionizantes, há possibilidades de estimular a germinação e o desenvolvimento de plantas e aumentar a produtividade. Estudos sobre os efeitos das radiações ionizantes em plantas cultivadas são conduzidos mediante a irradiação de sementes, plântulas e plantas em diversos estádios de desenvolvimento. A germinação, a emergência e a sobrevivência das plântulas, o desenvolvimento e a produção final das plantas são critérios comumente utilizados na avaliação da radiossensibilidade. Estudos, principalmente com sementes de cevada, aveia, centeio e trigo, mostram que o emprego de radiações pode aumentar ou reduzir o desenvolvimento e a produtividade de plantas. Existem evidências de que o teor de água das sementes torna-as mais sensíveis à ação dos mutagênicos, e sementes pré-embebidas antes da irradiação são muito mais radiosensíveis que sementes secas. Porém, a literatura referente aos efeitos de radiações ionizantes em sementes é esparsa e contraditória (MARCOS FILHO\& GODOY, 1974).

A atividade bioquímica também pode ser alterada pelo uso da radiação, como, por exemplo, a atividade enzimática. Dentre as enzimas potencialmente afetadas estão as fosfatases ácidas que catalizam a hidrólise de fosfato monoesteres e atuam em $\mathrm{pH}$ abaixo de 6,0 (PRAZERES et al., 2004). Outra enzima que pode ter sua atividade afetada é a alfa-amilase, enzima predominante sintetizada durante a germinação que atua, mobilizando as reservas de amido no endosperma (BEWLEY \& BLACK, 1994).

Este trabalho teve como objetivo avaliar os efeitos de diferentes doses de radiação gama $\left(\mathrm{Co}^{60}\right)$ na qualidade fisiológica de sementes de arroz.

\section{MATERIAL E MÉTODOS}

O experimento foi conduzido no Laboratório Didático de Análise de Sementes da Faculdade de Agronomia Eliseu Maciel da Universidade Federal de Pelotas (UFPel), utilizando sementes de arroz da cultivar 'BRS-7 Taim' cedidas pela EMBRAPA-CPACT, Pelotas, Rio Grande do Sul (RS). Os tratamentos com raios gama foram realizados em fonte de $\mathrm{Co}^{60}$ "Eldorado 78" (Atomic Energy of Canada, Ltd.) do Centro de Oncologia, Departamento de Radiologia, Faculdade de Medicina, UFPel, e as diferentes doses de radiação foram obtidas por meio da variação do tempo de exposição das sementes.

Primeiro ensaio: as sementes foram submetidas à radiação gama em fonte de $\mathrm{Co}^{60} \mathrm{com}$ as doses: 0; 1; 2,5 e 5Gy. Segundo ensaio: as sementes foram submetidas ao teste de envelhecimento segundo metodologia descrita pela AOSA (1983), visando avaliar o efeito da radiação sobre o vigor das sementes. Após o processo de envelhecimento acelerado, as sementes foram divididas em dois grupos, sendo uma parte irradiada ainda úmida, logo após o processo de envelhecimento acelerado, e a outra amostra foi primeiramente seca em estufa a $35^{\circ} \mathrm{C}$ por 24 horas. As doses de radiação gama utilizadas em ambas as amostras foram: 0; 1; 2,5 e 5Gy. Os resultados compararam níveis de umidades (sementes úmidas e secas após envelhecimento acelerado) e doses de radiação, caracterizando um bifatorial 2x4. Para as amostras submetidas à secagem, foi realizada análise da atividade das enzimas alfa amilase e da fosfatase 
ácida, segundo metodologia descrita pela Association of Official Analytical Chemists - AOAC (1975), nos tecidos vegetais obtidos das sementes (zero dias) e das plântulas (sete e 14 dias após a semeadura). Terceiro ensaio: as sementes foram submetidas ao envelhecimento acelerado, segundo metodologia descrita pela AOSA (1983), e foram secas em estufa a $35^{\circ} \mathrm{C}$ por 24 horas após o término do processo. O teor de água das sementes foi determinado antes e após secagem, de acordo com as Regras para Análises de Sementes - RAS (BRASIL, 1992). Após a secagem, as sementes foram submetidas às doses 0, 10, 25 e 50Gy de radiação gama.

Para avaliação do efeito das doses de radiação gama sobre as sementes, foram utilizados os seguintes testes: teste de germinação (TG), conforme descrito nas Regras para Análises de Sementes (BRASIL, 1992), índice de velocidade de germinação IVG (MAGUIRE, 1962) e crescimento de plântulas (comprimento de parte aérea e do sistema radicular em $\mathrm{mm}$ ) e massa seca total em gramas ), segundo KRZYZANOWSKI(1999).

Os três ensaios foram realizados em delineamento experimentais inteiramente casualizados, com quatro repetições. As análises estatísticas realizadas com o auxílio do programa SANEST (ZONTA \& MACHADO, 1986) foram a análise da variação e o desdobramento de médias pelo teste de Duncan em nível de 5\% de probabilidade de erro.

\section{RESULTADOS E DISCUSSÃO}

Ensaio I: Dentre as variáveis respostas avaliadas, não foram observadas diferenças entre os tratamentos nas variáveis IVG e massa da matéria seca
(Tabela 1). Foi observado efeito inibitório do crescimento da parte aérea em plântulas provenientes de sementes irradiadas com 1 e 5Gy, e esta última dose não difere estatisticamente na dose de 2,5Gy. Resultados semelhantes foram encontrados por BARROS \& ARTUR (2005), pois concluiram, ao tentar identificar a dose de redução do crescimento e a dose letal de soja irradiada com radiação gama, que o grau de radiosensibilidade varia com a espécie, o grau de umidade, o estádio de desenvolvimento, a dose de radiação empregada e, principalmente, o critério usado para medir o efeito biológico. MARCOS FILHO \& GODOY (1974) observaram que o comportamento das plantas a diferentes doses de radiação gama não obedece a um padrão definido, sendo esse efeito também observado neste estudo.

Ensaio II: No teste de germinação, houve diferença significativa entre sementes com diferentes teores de água (sementes secas e úmidas) em todas as doses de radiação estudadas, com exceção de 2,5Gy. Porém, não houve diferenças entre as doses de radiação utilizadas quando as sementes estavam úmidas (Tabela 2). De acordo com GUSMAN et al., apud VICCINI et al. (1997), a água atua como meio de difusão de mutagênicos físicos e químicos, bem como de radicais livres provenientes do processo de radiação, uma vez que elevados teores de água aumentam a atividade metabólica e, portanto, intensificam a vulnerabilidade das sementes à radiação.

Na comparação sobre o IVG, houve diferença significativa para a dose de 2,5Gy. Na tabela 2, pode ser observado que o maior teor de água influenciou negativamente o comprimento da parte aérea da plântula da testemunha quando comparado com as plântulas originadas das sementes secas. As doses de

Tabela 1 - Avaliação do índice de velocidade de germinação - IVG, germinação - G de sementes de arroz, comprimento do sistema radicular - SR, comprimento da parte aérea - PA e massa de matéria seca - MMS de plântulas de arroz, cultivar 'BRS-7 Taim', submetidas a diferentes dosagens de radiação gama.

\begin{tabular}{lccccc}
\hline Doses (Gy) & & G (\%) & SR (mm) & PA (mm) & MMS (mg) \\
\hline 0 & IVG & $76 \mathrm{a}$ & $11,0 \mathrm{~b}$ & $5,4 \mathrm{a}$ & $0,078 \mathrm{a}$ \\
1 & $7,70 \mathrm{ab}$ & $74 \mathrm{a}$ & $11,4 \mathrm{ab}$ & $5,4 \mathrm{a}$ & $0,084 \mathrm{a}$ \\
2,5 & $7,57 \mathrm{~b}$ & $74 \mathrm{a}$ & $12,1 \mathrm{a}$ & $5,2 \mathrm{ab}$ & $0,083 \mathrm{a}$ \\
5 & $7,47 \mathrm{~b}$ & $77 \mathrm{a}$ & $11,5 \mathrm{ab}$ & $5,0 \mathrm{~b}$ & $0,078 \mathrm{a}$ \\
$\mathrm{CV}$ & $8,10 \mathrm{a}$ & 4,82 & 25,80 & 22,54 & 21,74 \\
\hline
\end{tabular}

As médias não seguidas pela mesma letra, nas colunas, diferem entre si pelo teste de Duncan em nível de 5\% de probabilidade de erro. 
Tabela 2 - Avaliação do índice de velocidade de germinação - IVG, germinação de sementes de arroz, comprimento do sistema radicular SR, comprimento da parte aérea - PA e massa de matéria seca - MMS de plântulas de arroz, cultivar 'BRS-7 Taim’, submetidas a diferentes dosagens de radiação gama, envelhecidas artificialmente (úmidas) e secas após o envelhecimento (secas).

\begin{tabular}{|c|c|c|c|c|c|}
\hline \multirow{2}{*}{ Variável Resposta } & \multirow{2}{*}{ Teor de água } & \multicolumn{4}{|c|}{--Doses (Gy) } \\
\hline & & 0 & 1 & 2,5 & 5 \\
\hline \multirow{2}{*}{ IVG } & Seco & 7,60 а $\mathrm{AB}$ & 7,35 а BC & 6,97 b C & 8,14 a $A$ \\
\hline & Úmido & 7,80 а $\mathrm{A}$ & 7,80 а $\mathrm{A}$ & 8,00 a $A$ & 8,06 a $A$ \\
\hline \multirow{2}{*}{ Germinação (\%) } & Seco & 81 a A & 78 а $\mathrm{AB}$ & 74 a B & 81 a A \\
\hline & Úmido & 72 b A & $71 \mathrm{~b} \mathrm{~A}$ & 75 a A & 74 b A \\
\hline \multirow{2}{*}{$\mathrm{SR}(\mathrm{mm})$} & Seco & 12,00 a $A$ & 12,00 a $\mathrm{A}$ & 12,40 a $A$ & 11,30 a $\mathrm{A}$ \\
\hline & Úmido & 9,98 b B & 10,72 a $A B$ & 11,80 a $A$ & 11,60 a $\mathrm{A}$ \\
\hline \multirow{2}{*}{$\mathrm{PA}(\mathrm{mm})$} & Seco & 5,92 a $A$ & 5,36 a B & 5,36 a B & 4,77 b C \\
\hline & Úmido & 4,85 b B & 5,51 a A & 5,12 a $\mathrm{AB}$ & 5,30 a $\mathrm{AB}$ \\
\hline \multirow[b]{2}{*}{ MS (g) } & Seco & 0,089 а $\mathrm{A}$ & 0,090 a A & 0,087 a $A$ & 0,072 b B \\
\hline & Úmido & 0,066 b B & 0,079 b A & 0,079 a $\mathrm{A}$ & 0,083 a $A$ \\
\hline
\end{tabular}

As médias não seguidas pela mesma letra, nas colunas, diferem entre si pelo teste de Duncan em nível de 5\% de probabilidade de erro.

1 e 2,5Gy não apresentaram diferença estatística para o comprimento da parte aérea da plântula; porém, para a dose de 5Gy, as plântulas provenientes de sementes irradiadas com maior teor de água apresentaram maior crescimento da parte aérea do que as plântulas provenientes de sementes irradiadas secas. Comportamento semelhante foi observado no comprimento da parte aérea, onde diferenças entre plântulas provenientes de sementes úmidas e secas somente foram observadas nas doses zero e cinco Gy. Os resultados são semelhantes aos encontrados por VICCINI et al. (1997), os quais mostraram maior radiossensibilidade de sementes com maior teor de água para o comprimento da parte aérea das plântulas.

Para o sistema radicular, houve diferença entre as sementes irradiadas com os diferentes teores de água somente para as sementes não-irradiadas (dose zero). Para os demais tratamentos, embora esperado, não foram observadas diferenças no comprimento do sistema radicular em cada dose de radiação, quando comparadas sementes secas com sementes úmidas (Tabela 2). Os resultados não concordam com aqueles encontrados por VICCINI et al. (1997), os quais, trabalhando com sementes de milho submetidas à radiação gama, constataram que, na medida em que o teor de água decrescia, menor era o efeito prejudicial da radiação sobre o crescimento da raiz.

Os resultados apresentados indicam aumento de massa seca total (MMS) total das plântulas provenientes de sementes úmidas quando submetidas às doses de radiação 1; 2,5 e 5Gy, enquanto que, nas sementes secas, houve um comportamento diferente, pois as plântulas provenientes de sementes irradiadas secas na dose de 5Gy apresentaram mais massa seca que as demais. Quando comparado o efeito do teor de água entre sementes submetidas à mesma dose de radiação, observa-se que, na testemunha (zero Gy) e na dose de $1 \mathrm{~Gy}$, o maior teor de água prejudicou a produção de massa seca total, na dose de 2,5Gy, não foram observadas diferenças, enquanto que, na dose de 5Gy, as plântulas provenientes de sementes com maior teor de água produziram maior quantidade de MMS total.

Na atividade enzimática total da fosfatase ácida aos zero dias, observa-se pequena atividade da enzima, aos sete dias a atividade enzimática apresentou um aumento considerável, diminuindo a atividade aos 14 dias (Figura 1). Resultados semelhantes foram observados por PRAZERES et al. (2004) para sementes de soja, em que o pico de atividade máxima da enzima foi aos sete dias. Observa-se, na figura 1, que aos sete dias a atividade enzimática decresceu com o aumento das doses de radiação gama, sendo significativamente menor na dose de 5Gy. Na avaliação aos 14 dias, foi verificado um decréscimo para as doses de 1 e 2,5Gy em relação à testemunha, e a dose de 2,5Gy não diferiu estatisticamente da testemunha.

A atividade total da enzima alfa amilase foi maior na avaliação da semente aos zero dias e decresceu aos sete e 14 dias de germinação (Figura 2). Observou-se que a atividade da enzima decresceu com o aumento das doses de radiação gama aos zero dias. 


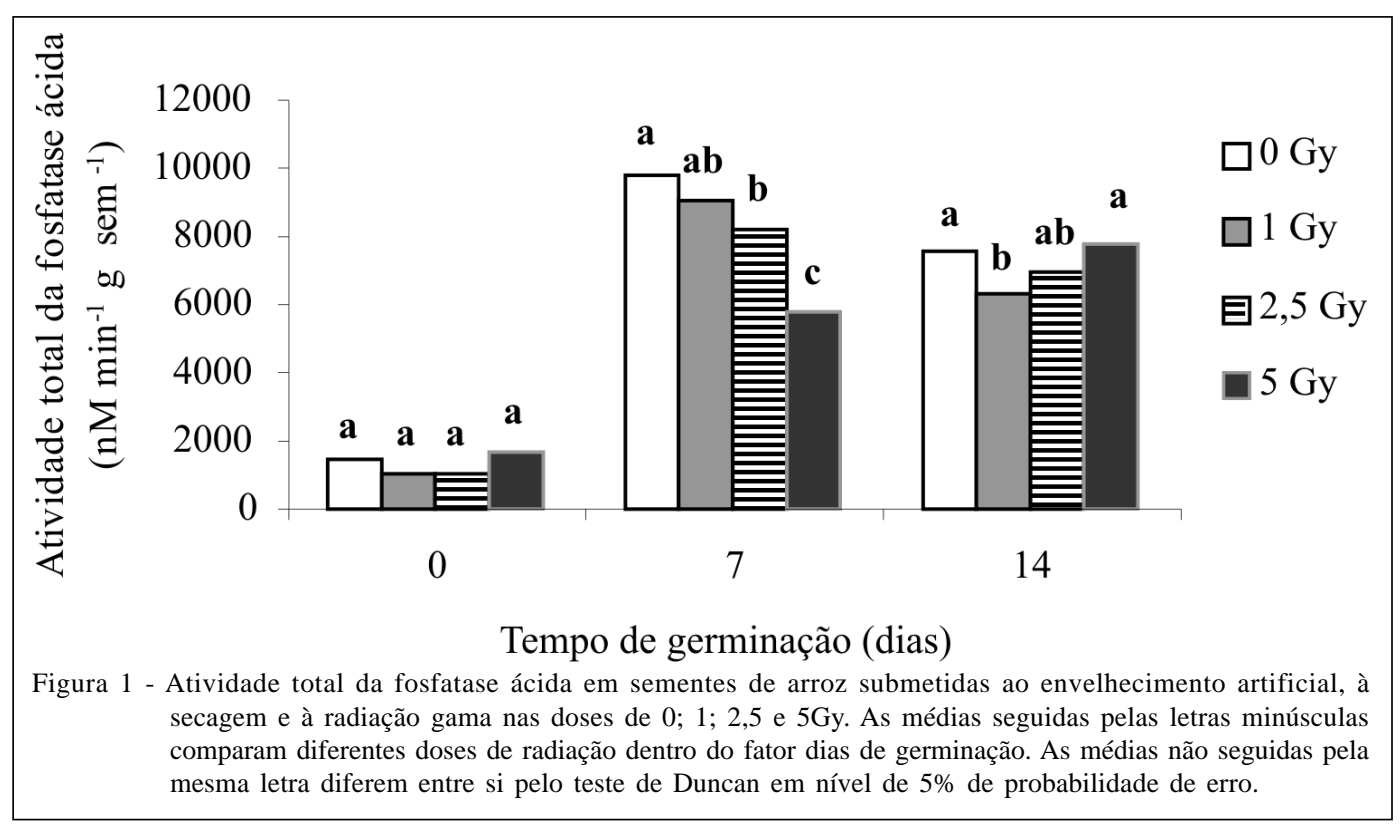

Já aos sete dias a atividade alfa amilase decresceu na dose de 2,5Gy, e, aos 14 dias, não houve diferença significativa na atividade enzimática da alfa amilase, nas diferentes doses de radiação gama.

Ensaio III: Os resultados desse ensaio demonstraram a redução do IVG com o aumento das doses de radiação gama (Tabela 3). Esses dados confirmam resultados obtidos por VICCINI et al. (1997), os quais, trabalhando com radiação gama em sementes de milho, afirmam que, ao aumento da dose de radiação, correspondeu o aumento dos danos, coincidindo com dados obtidos nos outros ensaios, que também evidenciaram maiores diferenças estatísticas no índice de velocidade de germinação. Resultados semelhantes também foram obtidos por RODRIGUES \& ANDO (2002), os quais concluíram que caracteres (como a altura) são afetados pela radiação, MANSOUR (2006),

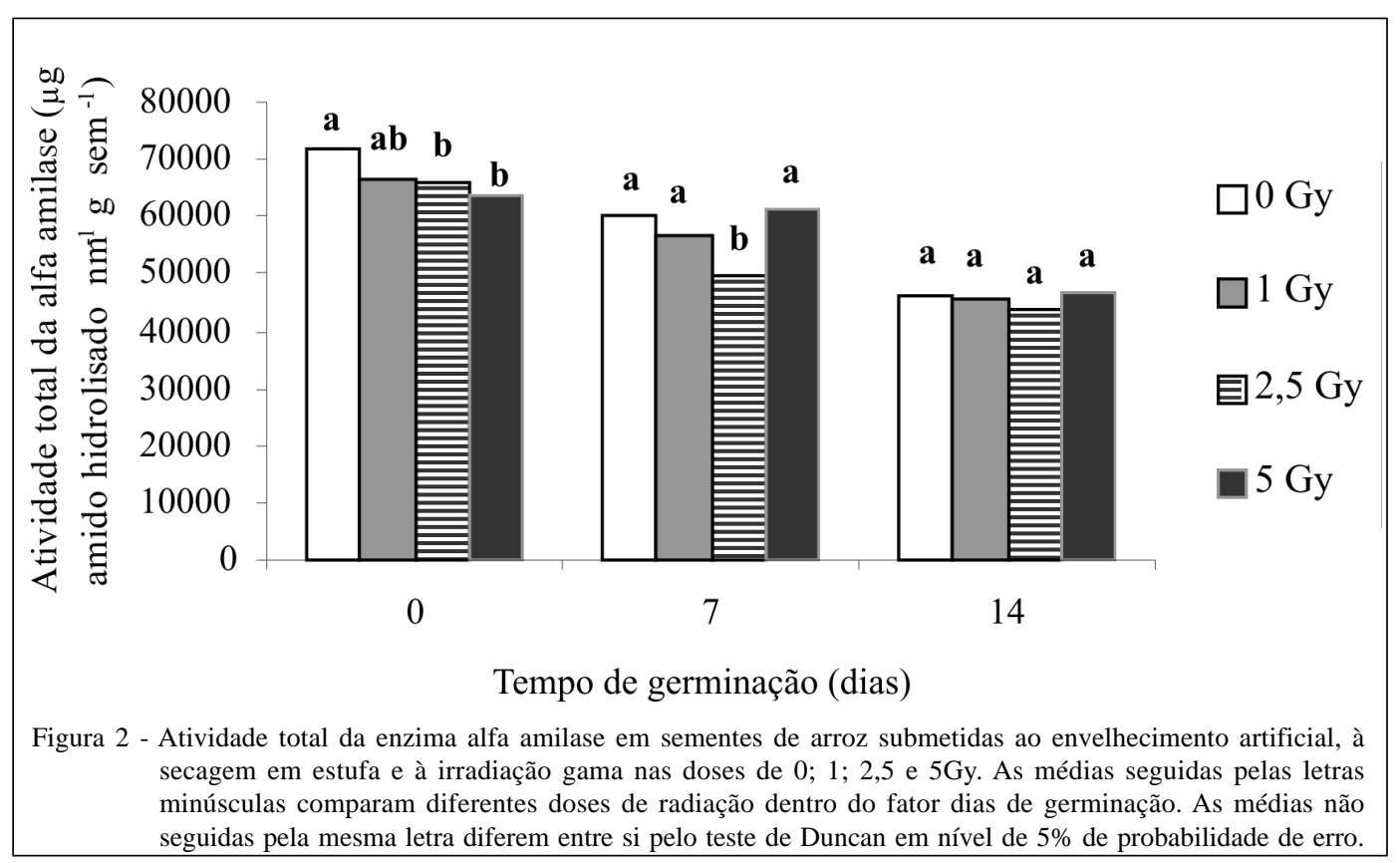

Ciência Rural, v.39, n.5, ago, 2009. 
Tabela 3 - Avaliação do índice de velocidade de germinação - IVG, germinação - G de sementes de arroz, comprimento do sistema radicular - SR, comprimento da parte aérea - PA e massa de matéria seca - MMS de plântulas de arroz, cultivar 'BRS-7 Taim', submetidas a diferentes dosagens de radiação gama.

\begin{tabular}{|c|c|c|c|c|c|}
\hline \multirow{2}{*}{ Doses (Gy) } & \multicolumn{5}{|c|}{ - } \\
\hline & IVG & G (\%) & SR (mm) & $\mathrm{PA}(\mathrm{mm})$ & MS (mg) \\
\hline 0 & $6,00 \mathrm{a}$ & $62 \mathrm{a}$ & $10,70 \mathrm{a}$ & $6,00 \mathrm{a}$ & $0,091 \mathrm{a}$ \\
\hline 10 & $6,00 \mathrm{a}$ & $67 \mathrm{a}$ & $10,70 \mathrm{a}$ & $6,00 \mathrm{a}$ & $0,090 \mathrm{a}$ \\
\hline 25 & $5,70 \mathrm{~b}$ & $64 \mathrm{a}$ & 10,70 a & $6,00 \mathrm{a}$ & 0,085 a \\
\hline 50 & $5,70 \mathrm{~b}$ & 59 a & 10,30 a & $5,70 \mathrm{a}$ & 0,079 a \\
\hline $\mathrm{CV}$ & 12,65 & 8,87 & 19,22 & 12,30 & 14,18 \\
\hline
\end{tabular}

As médias não seguidas pela mesma letra, nas colunas, diferem entre si pelo teste de Duncan em nível de 5\% de probabilidade de erro.

o qual identificou que o caráter tolerância ao frio na germinação sofre influência de radiação e por MARTINS et al. (2005), o qual concluiu que a radiação gama afeta a estatura, o ciclo, o número de afilhos, o número de panículas e o índice de afilhos férteis em arroz.

\section{CONCLUSÃO}

As doses de radiação gama estudadas não afetam a qualidade fisiológica das sementes de arroz.

\section{REFERÊNCIAS}

ASSOCIATION OF OFFICIAL ANALYTICAL CHEMISTS Official methods of analysis. 12.ed. Washingtonn, D.C., USA, 1975. 1094p.

ASSOCIATION OF OFFICIAL SEED ANALYSTS - AOSA. Washington, 1983. 93p. (Contribuition,32).

BAHL. J.R.; GUPTA, P.K. Chlorophyll mutations in mungbcan (Vigna radiata (L.) Wilczek). Theoretical and Applied Genetics, Berlin, v.63, p.23-26, 1982.

BARROS, A.C.; ARTUR, V. Determinação experimental da dose de redução do crescimento (GR50) e da dose letal (LD50) de soja irradiada por raios gama. Arquivos do Instituto Biológico, São Paulo, v.72, n.2, p.249-253, 2005.

BEWLEY, J.D.; BLACK, M. Seeds: physiology of development and germination. 2.ed. New York: Plenum, 1994. 445p.

BRASIL. Ministério da Agricultura e Reforma Agrária. Regras para análise de sementes. Brasília: SNDA/DNDV/CLAV, 1992. 365p.

BROCK, R.D. Mutagenesis and crop improvement. In: CARLSON, P.S. Biology of crop productivity. New York,:Academic, 1980. p.383-409.

BUMP, E. A. et al. Radiosensitization of hypoxic tumor cells by depletion of intracellular glutathione. Science, Washington. v.217, p.544-545, 1982.
CONGER, B.V.; CARABIA, J.V. Modification of the effectives of fission neutrons versus 60 Co gamma radiation in barley seeds by oxygen and seed water content. Radiation Botany, Great Britain, v.12, p.411-420, 1972.

GAUL, $\mathrm{H}$. Mutagen effects observable in the first generation. In: MANUAL MUTATION BREEDING, IAEA. 1969, New Delhi Proceedings... Vienna: FAO/IAEA Division 1971. 106.1970.

GUDKOV, I.N.; GRODZINSKY, D.M. Cell radiosensitivity variation in synchronouly-dividing root meristems of Pisum sativum L. during the mitotic cycle. International Journal of Radiation Biology, Bristol, v.41, n.4, p.401-409, 1982.

IQBAL, J.; ZAHUR, M.S. Effects of acute gamma irradiation and developmental stages on growth and yield of rice plants. Radiation Botany, Great Britain, v.15, p.231-240, 1975. Disponível em: $<\mathrm{h} \mathrm{t} \mathrm{t} \mathrm{p} \mathrm{:} \mathrm{/} \mathrm{/} \mathrm{w} \mathrm{w} \mathrm{w.} \mathrm{s} \mathrm{c} \mathrm{i} \mathrm{e} \mathrm{n} \mathrm{ce} \mathrm{di} \mathrm{re} \mathrm{c} \mathrm{t.} \mathrm{c} \mathrm{o} \mathrm{m/}$ science?_ob=ArticleURL\&_udi=B75CM-4H5FD3X$4 \&$ _user $=687358 \&$ _rdoc $=1 \&$ fmt $=$ \&_orig $=$ search\&_sort $=\mathrm{d} \&$ view $=\mathrm{c}$ \&_acct $=$ C $000037899 \&$ \& version $=1 \&$ \&_urlVersion $=0$ \& userid $=687358 \& \mathrm{md} 5=9 \mathrm{c} 64 \mathrm{c} 180 \mathrm{a} 81 \mathrm{ce} 8 \mathrm{~d} 935 \mathrm{e} 413 \mathrm{f} 22 \mathrm{dadae} 5 \mathrm{a} 3>$. Doi: 10.1016/S0033-7560(75)80022-6.

KRZYZANOWSKI, F.C. et al. Vigor de sementes: conceitos e testes. Londrina: ABRATES, 1999. 90p.

KUMAR, G. Modification of radiation induced genetic damage and impaired DNA synthesis by thiourea treatment in Solanum incanum L. Cytologia, Tokyo, v.56, p.117-123, 1991.

MAGUIRE, J.D. Speed of germination-aid in selection and evaluation for seedling emergence and vigor. Crop Science, Madison, v.1, n.1, p.176-177, 1962.

MANSOUR, D.H. Indução de mutação em sementes de arroz (Oryza sativa L.) e seleção de possiveis mutantes M2 para dormência e tolerancia ao frio na germinação. 2006. 52f. Dissertação (Mestrado em Ciência e Tecnologia de Sementes) - Faculdade de Agronomia Eliseu Maciel. Universidade Federal de Pelotas

MARCOS FILHO, J.; GODOY, O.P. Efeitos de irradiação de sementes sobre a produtividade do feijoeiro. O Solo, Piracicaba, v.1, p.18-22, 1974.

Ciência Rural, v.39, n.5, ago, 2009. 
MARTINS, A.F. et al. Variabilidade para caracteres morfológicos em mutantes de arroz. Ciência e Agrotecnologia, Lavras, v.29, n.6, p.1215-1223, 2005.

MIKAELSEN, K. Mutagenic effectiveness and efficiency of gamma rays, fast neutrons and ethyl methane sulphonate in rice. In: RICE BREEDING WITH INDUCED MUTATIONS III, IAEA, 1969, New Delhi Proceedings... Vienna: FAO/ IAEA Division 1971. ,p. 91-96.

PIMENTEL, M.C.G. Indução de aberrações cromossômicas estruturais em milho (Zea mays L.) por radiação gama. 1990. 131f. Dissertação (Mestrado Gernética e Melhorasmento) - Programa de Pós-Graduação em Genética e Melhoramento, UFV, Viçosa, MG.

PLEWA, M. J. et al. . Induced forward mutation at the yg2 locus and a comparison with the ABCW relationship. Maize Genetics cooperation Newsletter, Columbia, v.57, p.147149, 1993.

PRAZERES, J.N. et al. Acid phosphatase activities during the germination of Glycine max seeds. Plant Phisyology and Biochemistry, v.42, p. 15- 20, 2004. Disponível em: <http:/ / w w w. s c i e $\mathrm{n}$ c e d i $\mathrm{r}$ e $\mathrm{c}$. c o m / science?_ob=ArticleURL\&_udi=B6VRD-4BG2TFX$4 \& \_u s e r=687358 \& \_r d o c=1 \& \_f m t=\& \_o r i g=$ search \&_sort $=\mathrm{d} \&$ view $=$ c\&_acct $=$ C000037899\&_version $=1 \&$ \&_urlVersion $=0 \&$ _userid=687358\&md5=d3923975810c90340f119a752be16477 > . Doi: 10.1016/j.plaphy.2003.10.009.

RODRIGUES, L.R.F.; ANDO, A. Caracterização e avaliação de três grupos de arroz-de-sequeiro de diferentes procedências por meio da sensitividade à radiação gama. Bragantia, Campinas, v.61, n.1, p.17-23, 2002. Disponível em: <http://www.scielo.br/ scielo.php? script =sci_art text \& pid = S 0006 $87052002000100004 \& \operatorname{lng}=$ en\&nrm=iso\&tlng=pt $>$. Doi: $10.1590 /$ S0006-87052002000100004.

SANTOS, M.V.F.D.L. Resposta à radiação gama em sementes de milho (Zea mays L.) sob a influência de agentes físicos e químicos. 1993. 131f. Dissertação (Mestrado Genética e Melhoramento) Programa de PósGraduação em Genética e Melhoramento. Universidade Federal de Viçosa, Viçosa, MG,

VICCINI, L. F. et al. Resposta de sementes de milho à radiação gama em função do teor de água. Bragantia, Campinas, v.56, n.1, p.1-7, 1997. Disponível em: <http://www.scielo.br/ scielo.php? script = sci_art text \& pid=S 0006 $87051997000100001 \& \operatorname{lng}=$ en $\&$ nrm $=$ iso\&tlng=pt $>$. Doi: 10.1590/S0006-87051997000100001.

ZONTA, E.P.; MACHADO, A.A. Sistema de análise estatística para microcomputadores- SANEST. Pelotas: UFPel, Instituto de Física e Matemática, 1986. 150p. 